\title{
CDC42 drives RHOA activity and actin polymerization during capacitation
}

\author{
Tania Reyes-Miguel ${ }^{1}$, Ana L Roa-Espitia, Rafael Baltiérrez-Hoyos² and \\ Enrique O Hernández-González ${ }^{1}$ \\ ${ }^{1}$ Departamento de Biología Celular, Centro de Investigación y Estudios Avanzados del Instituto Politécnico \\ Nacional, San Pedro Zacatenco, Gustavo A. Madero, México City, México and ${ }^{2}$ Universidad Autónoma Benito \\ Juárez de Oaxaca, Facultad de Medicina y Cirugía, Oaxaca, Oaxaca, México \\ Correspondence should be addressed to E O Hernández-González; Email: eoton@cell.cinvestav.mx
}

\begin{abstract}
Mammalian sperm cells acquire fertilizing capacity as a result of a process termed capacitation. Actin polymerization is important for capacitation; inhibiting actin polymerization prevents the adhesion and fusion of the sperm with the ovule. The main function of RHO proteins CDC42 and RHOA is to direct actin polymerization. Although these two RHO proteins are present in mammalian sperm, little is known about their role in capacitation, the acrosome reaction, and the way in which they direct actin polymerization. The purpose of this study was to determine the participation of CDC42 and RHOA in capacitation and the acrosome reaction and their relationship with actin polymerization using guinea pig sperm. Our results show that the inhibition of CDC42 and RHOA alters the kinetics of actin polymerization, capacitation, and the acrosome reaction in different ways. Our results also show that the initiation of actin polymerization and RHOA activation depend on the activation of CDC42 and that RHOA starts its activity and effect on actin polymerization when CDC42 reaches its maximum activity. Given that the inhibition of ROCK1 failed to prevent the acrosomal reaction, the participation of RHOA in capacitation and the acrosomal reaction is independent of its kinase 1 (ROCK1). In general, our results indicate that CDC42 and RHOA have different roles in capacitation and acrosomal reaction processes and that CDC42 plays a preeminent role.

Reproduction (2020) 160 393-404
\end{abstract}

\section{Introduction}

Capacitation consists of a series of well-synchronized events experienced by mammalian sperm after spending time in the oviduct. These events allow sperm cells to acquire fertilizing ability. A capacitated sperm cell can be recognized by the presence of two conditions: hypermotility and acrosome reaction (AR) induction. These two events allow sperm to pass through the envelopes of the ovule and adhere and fuse with the plasma membrane of the ovule (Gervasi \& Visconti 2016). These events occur in response to changes in the environment to which sperm are exposed, whether the oviductal environment or a specific culture medium, involving the activation of different signaling pathways that lead to the intracellular increase of $\mathrm{Ca}^{2+}, \mathrm{Cl}^{-}$, and $\mathrm{HCO}_{3}^{-}$; plasma membrane hyperpolarization; lipid membrane remodeling; cAMP-related signaling pathway activation; an increase in protein phosphorylation in Tyr residues (Visconti et al. 1995a,b, Stival et al. 2016); and the remodeling of actin and spectrin cytoskeletons (Breitbart et al. 2005, Bastian et al. 2010, Roa-Espitia et al. 2016). It is important to note that these changes have been reported mainly in human, mouse, bovine, pig and guinea pig sperm (Breitbart et al. 2005, Bastian et al. 2010, Gervasi \& Visconti 2016, Stival et al. 2016).

The polymerization of actin that occurs in the course of capacitation seems to be a generalized process in mammalian sperm, as has been reported for different species, from human beings to bovines, pigs, mice, buffaloes, and guinea pigs (Moreno-Fierros et al. 1992, Brener et al. 2003, Bernabo et al. 2011, Naresh \& Atreja 2015, Angeles-Floriano et al. 2016, Roa-Espitia et al. 2016). In its polymeric status (F-actin), actin has been mainly found in the apical regions of the acrosomal, equatorial, and postacrosomal head, as well as in the flagellum of mature sperm cells (Brener et al. 2003, Naresh \& Atreja 2015, Angeles-Floriano et al. 2016, Roa-Espitia et al. 2016). The specific location of the actin cytoskeleton and the inhibition of actin polymerization during capacitation show that F-actin has a role in processes such as motility (Azamar et al. 2007, Itach et al. 2012), the AR (Spungin et al. 1995, Hernandez-Gonzalez et al. 2000, Brener et al. 2003, Cabello-Agueros et al. 2003), and the rearrangement of proteins required by sperm for fertilization, such as Izumo (Sosnik et al. 2009). 
The way in which actin polymerization is regulated during capacitation has been associated with different mechanisms. Evidence suggests that at least three different signaling pathways could be related to actin polymerization during capacitation: (1) the pathway associated with PKA/PLC/ PKC/PLD/Cofilin, this signaling pathway has been primarily related to human sperm (Breitbart et al. 2005, Megnagi et al. 2015); (2) the pathway associated with RHOA or RAC1/ROCK-1/ LIMK-1/Cofilin has been related described for bovine and mouse sperm (Fiedler et al. 2008, Romarowski et al. 2015); and (3) for mouse and guinea pig sperm the pathway associated with CDC42/WASP/ARP2/3 was reported (Delgado-Buenrostro et al. 2005, 2016, Angeles-Floriano et al. 2016). Blocking CDC42 or RHOA activity is known to inhibit actin polymerization and the normal course of the AR (Brener et al. 2003, Baltierrez-Hoyos et al. 2012, Angeles-Floriano et al. 2016). Data show that RHOA and CDC42 could be the main $\mathrm{RHO}$ proteins directing actin polymerization during capacitation. Both of these small GTPases present a conserved localization in human, mouse, guinea pig, bovine, pig, ram, rat sperm; they are located in the acrosomal region and the flagellum (Ducummon \& Berger 2006, Baltierrez-Hoyos et al. 2012, Salvolini et al. 2013, Angeles-Floriano et al. 2016, DelgadoBuenrostro et al. 2016). However, the dynamics of these proteins during capacitation and how they relate to each other to achieve actin polymerization during capacitation are still unknown.

CDC42 and RHOA are ubiquitously expressed, and although both $\mathrm{RHO}$ proteins participate in actin polymerization, these $\mathrm{RHO}$ proteins are known to have different dynamics in different cell lines; as a result, they give rise to the formation of different cell structures. The activation of CDC42 results in the formation of filopodia, and the activation of RHOA is associated with the formation of stress fibers (Jaffe \& Hall 2005, Hall et al. 2011). Mammalian sperm expresses both CDC42 and RHOA; however, these cells do not form cell projections such as filopodia or lamellipodia. Therefore, $\mathrm{RHO}$ proteins expressed in sperm must have functions specifically related to sperm physiology. Due to the limited amount of cytoplasm contained in the sperm cell, stress fibers have been observed as short filaments associated with the external plasma and acrosomal membranes (Fouquet et al. 1990, Peterson et al. 1990, Hernandez-Gonzalez et al. 2000).

The purpose of the present study was to determine the role of CDC42 and RHOA in capacitation and the AR. We also focused on the participation of CDC42 and RHOA in actin polymerization dynamics during capacitation, on how specific inhibitors for these $\mathrm{RHO}$ proteins affect these sperm processes, and on whether there the activities of CDC42 and RHOA are interrelated. Finally, we studied the participation of RHO kinases (ROCks) in the capacitation, AR and actin polymerization.

\section{Materials and methods}

\section{Antibodies and reagents}

Most of the reagents used in this study were purchased from Sigma-Aldrich Co. Protease inhibitor (Complete ${ }^{\mathrm{TM}}$ cocktail tablets) were ordered from Roche Diagnostics and Molecular Biochemicals. Nitrocellulose membranes, acrylamide, $\mathrm{N}, \mathrm{N}^{\prime}$-methylene-bisacrylamide, and sodium dodecyl sulfate (SDS) were obtained from Bio-Rad Laboratories. Anti-RHOA (Ab6882) was purchased from Abcam. Anti-CDC42 (sc-57), anti-ROCK1 (sc-5560), and anti-ROCK2 (sc-5561), were acquired from Santa Cruz Biotechnology Inc. C3 RHO inhibitor (CT04) was purchased from Cytoskeleton Inc (Denver, CO). Secondary antibodies labeled with horseradish peroxidase (HRP) or TRITC were obtained from Jackson Immunoresearch Laboratories Inc. Enhanced chemiluminescence (ECL) reagent was purchased from Amersham or Millipore. Secramine A was kindly donated by Kirchhausen Lab (Harvard Medical School) and the Hammond Lab (University of Louisville), synthesized by Bo Xu and GB Hammond of the University of Louisville.

\begin{abstract}
Animals
Male Dunkin-Hartley guinea pigs (Cavia porcellus) weighing 600-800 g were obtained from the Cinvestav-IPN vivarium. All animal experiments and handling procedures were approved by the Internal Ethics committee for Laboratory Animal Care and Use of CINVESTAV-IPN (CICUAL No. 0122-14, April 2017) and conducted following the American Veterinary Medical Association guidelines. Efforts were made to minimize the potential for animal pain, stress, or distress.
\end{abstract}

\section{Sperm capacitation}

Guinea pig sperm were collected from the animals' vas deferens per published procedure (Mujica et al. 1991). Sperm were resuspended in $154 \mathrm{mM} \mathrm{NaCl}$ and a $25 \mathrm{mM}$ HEPES buffer at $\mathrm{pH}$ 7.2. For the non-capacitation condition, sperm were incubated in a solution containing $154 \mathrm{mM} \mathrm{NaCl}$ and a 25-mM-HEPES buffer at $\mathrm{pH}$ 7.2. For the capacitation condition, sperm were incubated in Tyrode's medium $(116.7 \mathrm{mM} \mathrm{NaCl}$, $2.8 \mathrm{mM} \mathrm{KCl}, 11.9 \mathrm{mM} \mathrm{NaHCO}_{3}, 0.3 \mathrm{mM} \mathrm{NaH}_{2} \mathrm{PO}_{4}, 0.49 \mathrm{mM}$ $\mathrm{MgCl}_{2}, 0.25 \mathrm{mM}$ sodium pyruvate, and $20 \mathrm{mM}$ sodium lactate) at $37^{\circ} \mathrm{C}$ and $\mathrm{pH}$ 7.6. Sperm concentration was maintained at $35 \times 10^{6} \mathrm{sperm} / \mathrm{mL}$ in all experiments. The process of capacitation is asynchronous; therefore, to define the kinetics of capacitation and acrosomal reaction at defined times $(0$, $15,30,60$, and $90 \mathrm{~min}$ ) of incubation, small aliquots of the sperm suspension were placed on slides and the percentage of motile sperm and the acrosomal reaction were estimated. Those samples that showed low levels of motility (less than $70 \%$ ) were discarded. Under these conditions, between the 60 to 70 min of capacitation, the sperm initiate the acrosomal reaction.

Sperm cells were also capacitated in the presence of different drugs: Secramine A (SecA, $5 \mu \mathrm{M})$, C3 toxin $(1 \mu \mathrm{g} /$ $\mathrm{mL})$, latrunculin $\mathrm{A}(5 \mu \mathrm{M})$, and Y-27632 (0-400 nM), which were added since the beginning of capacitation. Any change is indicated in the text. 


\section{Acrosome reaction assay}

\section{Spontaneous acrosome reaction}

Sperm were capacitated in Tyrode's medium, incubating them for $90 \mathrm{~min}$. Immediately, the sperm were prepared to evaluate the spontaneous AR (sAR) using the CTC test.

\section{Induced acrosome reaction}

Sperm were capacitated in Tyrode's medium for 50 min; afterward, AR was induced (iAR) adding progesterone (10 $\mu \mathrm{M})$, and the sperm cells were incubated another $20 \mathrm{~min}$. The effects of the different inhibitors on the progesterone-induced AR (iAR) were determined capacitating sperm during $50 \mathrm{~min}$ in the presence of any of the following inhibitors: $\mathrm{C} 3(1 \mu \mathrm{g} / \mathrm{mL})$ or SecA $(5 \mu \mathrm{M})$ or $\mathrm{Y}-27632(100 \mathrm{nM})$. Next, progesterone $(10 \mu \mathrm{M})$ was aggregated, and the sperm were incubated for another $20 \mathrm{~min}$. Through the CTC assay was assessed AR. $\mathrm{iAR}=\%$ de $\mathrm{AR}(70 \mathrm{~min})-\%$ de AR (50 min).

\section{Sperm viability assay}

To know whether the drugs used in this work affect sperm viability, this was determined using the methodology described by Brito et al. (2003). Sperm were capacitated in Tyrode's medium for $90 \mathrm{~min}$ in the presence of some of the following inhibitors: C3 $(1 \mu \mathrm{g} / \mathrm{mL})$, Sacramine A $(5 \mu \mathrm{M})$ and Y-2763 (100 nM). Propidium iodide (PI) solution $(1 \mu \mathrm{g} / \mathrm{mL})$ was added to sperm samples to a 1:1 ratio and incubated at room temperature for $30 \mathrm{~min}$. Immediately, sperm were washed, and under an epifluorescence microscope, the number of stained sperm was counted (500 cells X sample, $n=3$ ). As a control, sperm capacitated in the absence of any of the inhibitors were also stained with PI. When the samples had a viability less than $80 \%$, they were discarded. Data are shown in Fig. $1 \mathrm{G}$.

\section{Assay to detect and quantify F-actin}

F-actin was quantified using the method described by Roa-Espitia et al. (2016). Thus, non-capacitated and capacitated sperm were fixed (1.5\% formaldehyde and $0.1 \%$ glutaraldehyde, in PBS). After $1 \mathrm{~h}$, the sperm cells were collected by centrifugation ( $600 \mathrm{~g}$ for $3 \mathrm{~min}$ ) and the cellular pellet was incubated in $50 \mathrm{mM} \mathrm{NH}_{4} \mathrm{Cl}(10 \mathrm{~min})$ and rinsed three times with PBS. Microscope slides were prepared. Sperm cells were permeabilized in PBS with Triton (0.1\%) for 20 min at room temperature and then washed with PBS.

Sperm were incubated for $1 \mathrm{~h}$ at $37^{\circ} \mathrm{C}$ with phalloidinTRICT or phalloidin-FITC (1:25) and washed five times in PBS. Samples were mounted with glass-coverslips in Gelvatol. All fluorescence images were obtained using a confocal laser scanning microscope (Leica TCS SP8), and 500 sperm cells were analyzed using the NIS-Elements 3.1 imaging software.

\section{Chlortetracycline assay}

The procedure used in this essay was first described by Ward and Storey (1984), and it has been adapted to guinea pig sperm (Maldonado-Garcia et al. 2017). At specific times of capacitation, $45 \mu \mathrm{L}$ of sperm suspension was mixed with $45 \mu \mathrm{L}$ chlortetracycline (CTC) solution (750 mM CTC in $130 \mathrm{mM}$ $\mathrm{NaCl}, 5 \mathrm{mM}$ cysteine, $20 \mathrm{mM}$ TRIS, $\mathrm{pH}$ 7.8) and incubated for $20 \mathrm{~s}$ in a water bath at $37^{\circ} \mathrm{C}$. Immediately after incubation, the CTC-sperm suspension was fixed with glutaraldehyde $(0.1 \%$, final concentration) in $0.5 \mathrm{mM}$ TRIS $(\mathrm{pH} \mathrm{7.4)}$ at room temperature. A $10 \mu \mathrm{L}$ sample of the CTC-sperm suspension was smeared onto a glass slide and covered with a coverslip, adequately sealed, and stored for $48 \mathrm{~h}$ at $-20^{\circ} \mathrm{C}$ to clear strong background fluorescence. The CTC solution was kept in a lightshielded container at $4^{\circ} \mathrm{C}$ at all times. All fluorescence images were obtained using an epifluorescence microscope (Olympus BX5) and registered using the Nis-Element 3.1 software. Five hundred sperm cells per sample were classified as expressing one of three CTC staining patterns: F pattern, characterized by faint fluorescence in the acrosome region, typical of noncapacitated acrosome-intact cells; B pattern, characterized by bright fluorescence in the acrosomal region and a band along the equatorial segment, typical of capacitated acrosome-intact cells; and AR pattern, characterized by fluorescence in the post-acrosomal region and the equatorial segment, typical of physiologically capacitated acrosome-reacted cells. CTC excitation at 330-380 nm, emission at $420 \mathrm{~nm}$.

\section{CDC42 activation assay}

To detect CDC42-GTP specifically, we used the CDC42 G-LISA Activation Assay Biochem Kit (BK127. Cytoskeleton Inc., Denver, CO, USA) per the manufacturer's instructions and as reported by Baltierrez-Hoyos et al. (2012). Thus, $50 \mu \mathrm{L}$ of duplicate samples of sperm lysates from non-capacitated and capacitated sperm $(0,5,10,20,30,60$, and 90 min $)$ at a concentration of $0.3 \mathrm{mg}$ protein $/ \mathrm{mL}$ were added to each well. Plain lysis buffer and a standard curve of constitutively active CDC42 protein protein were added to duplicate wells as a blank and positive control, respectively. After binding, antiCDC42 primary antibody was added to each well followed by secondary antibody labeled HRP, which was developed by adding HRP reagent. Each well was read at OD $490 \mathrm{~nm}$ on a 96-well plate spectrophotometer. Control sperm cells were capacitated in the presence of SecA $(5 \mu \mathrm{M})$. Purified GTPbound CDC42, supplied by the manufacturer, was used to establish a standard curve.

\section{RHOA activity assay}

RHOA-GTP was evaluated by pull-down assay using the RHOA Pull-down Activation Assay Biochem Kit (Cytoskeleton). Proteins $(300 \mu \mathrm{g})$ from non-capacitated sperm, capacitated sperm, or sperm capacitated in the presence of inhibitors (1 $\mu \mathrm{g} / \mathrm{mL}$ C3 or $5 \mu \mathrm{M}$ SecA) were incubated with $50 \mu \mathrm{g}$ agarose-conjugated Rhotekin-RBD at $4{ }^{\circ} \mathrm{C}$ for $1 \mathrm{~h}$. Proteins not bound to rhotekin-RBD were recovered by centrifugation at $5000 \mathrm{~g}$ at $4^{\circ} \mathrm{C}$ for $3 \mathrm{~min}$, after three washes. The RHOAGTP associated with Rhotekin-RBD was released by boiling in Laemmli sample buffer and separated by SDS-PAGE, transferred to nitrocellulose membranes, and then subjected to immunoblot analysis. 
A
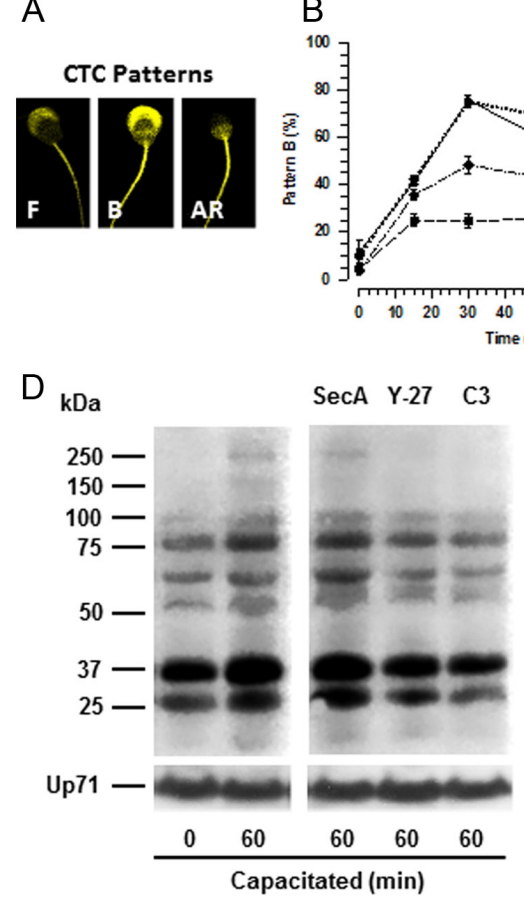

D

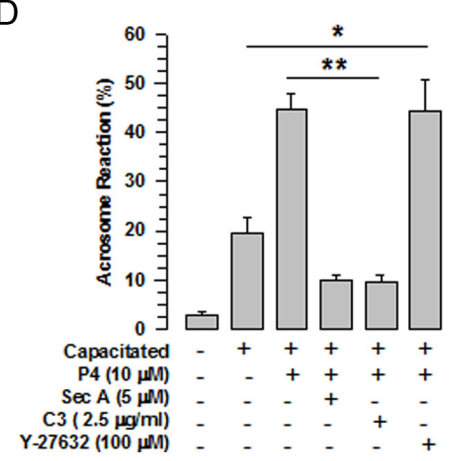

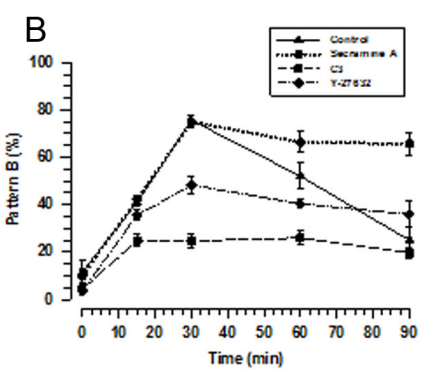

C

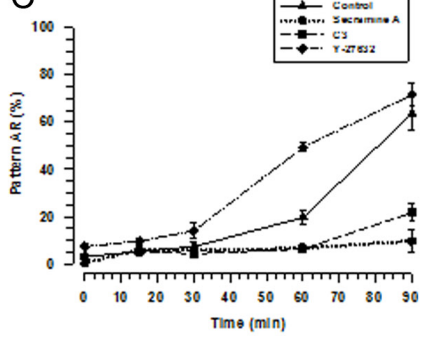

Figure 1 Actin polymerization antagonists alter capacitation and acrosomal reaction differently. (A) CTC staining patterns. F, non-capacitated sperm; B, capacitated sperm; $A R$, sperm that have experienced acrosomal reaction, corresponding to the spontaneous acrosomal reaction. (B) Pattern B was assessed in sperm capacitated in the absence or presence of $\mathrm{C} 3$ toxin $(1 \mu \mathrm{M})$ or Secramine $(5 \mu \mathrm{M})$. AR pattern of CTC staining. (C) The AR pattern was assessed in sperm capacitated in the absence or presence of $\mathrm{C} 3$ toxin $(1 \mu \mathrm{M})$, Secramine $(5 \mu \mathrm{M})$, or $\mathrm{Y}-27632(100 \mathrm{nM})$. AR pattern of CTC staining. Mean \pm S.E.M., $n=3$ independent experiments. Five hundred cells per experiment were counted. (D) Whole extracts obtained from sperm capacitated under different conditions were used to determine the PYP levels. Proteins were separated by SDS-PAGE and transferred to nitrocellulose membranes. PYP was analyzed using an anti-p-Tyr antibody. SecA, Secramine A $(5 \mu \mathrm{M})$; Y-27, Y-27632 (100 nM). C3

$(1 \mu \mathrm{g} / \mathrm{mL})$. The image is a representative of three independent experiments. (E)

Densitometric analysis of PYP. Means \pm S.E.M., $n=3$ independent experiments. (F) Acrosome reaction progesterone-induced. In sperm capacitated in the presence or absence of C3, SecA, or Y-27632, the AR was induced by progesterone and compared with SAR. Means \pm S.E.M., $n=3$ independent experiments. (G) Sperm viability assessment. Sperm were capacitated in the presence of any of the following inhibitors: SecA (5 $\mu \mathrm{M}), \mathrm{C} 3$ $(1 \mu \mathrm{g} / \mathrm{mL})$ or Y-27632 (100 nM). After $90 \mathrm{~min}$ of incubation in Tyrode's medium, sperm viability was assessed using propidium iodide (see Materials and methods). Means \pm S.E.M., $n=3$ independent experiments.

\section{Western blot and densitometry assays}

Non-capacitated sperm and sperm capacitated at different times were centrifuged ( $600 \mathrm{~g}$, for $3 \mathrm{~min}$ ) and suspended in RIPA buffer $(25 \mathrm{mM}$ TRIS $\mathrm{HCl} \mathrm{pH} 7.6,150 \mathrm{mM} \mathrm{NaCl}, 1 \%$ NP- $40,1 \%$ sodium deoxycholate, $0.1 \%$ SDS) supplemented with protease inhibitors $(5 \mathrm{mg} / \mathrm{mL}$ soybean trypsin inhibitor, $100 \mathrm{mg} / \mathrm{mL}$ benzamidine, $30 \mathrm{mg} / \mathrm{mL}$ pepstatin, $30 \mathrm{mg} /$ $\mathrm{mL}$ leupeptin, $30 \mathrm{mg} / \mathrm{mL}$ aprotinin, $1 \mathrm{mM}$ PMSF diluted in dimethylsulfoxide, $20 \mathrm{mg} / \mathrm{mL}$ iodoacetamide, $1 \mathrm{mM}$ sodium orthovanadate, $10 \mathrm{mM}$ sodium fluoride, $10 \%$ glycerol, $2.5 \%$ complete mini protease inhibitor cocktail, 1 tablet diluted in $1 \mathrm{~mL} \mathrm{H} \mathrm{H}_{2} \mathrm{O}$ ). Samples were then incubated for $20 \mathrm{~min}$ in ice and centrifuged $\left(5000 \mathrm{~g}\right.$ ) for $30 \mathrm{~min}$ at $4{ }^{\circ} \mathrm{C}$. Supernatants were collected, and protein concentration was determined using the Bradford assay. Samples were then boiled for $5 \mathrm{~min}$ in sample Laemmli buffer $\mathrm{pH} 7$ and separated by SDS-PAGE to be subsequently transferred to nitrocellulose membranes and blocked with $5 \%$ skim milk in PBS added with $1 \%$ Triton $(\mathrm{pH}$ 7.5). The membranes were incubated overnight at $4^{\circ} \mathrm{C}$ with the primary antibodies: anti-CDC42 (1:1000), anti-RHOA (1:500), anti-ROCK1 (1:1000), and anti-ROCK2 (1:1000).
Next, membranes were incubated with their respective secondary antibody: HRP-conjugated anti-rabbit $(1: 10,000)$, HRP-conjugated anti-mouse (1:5000), or HRP-conjugated anti-goat (1:5000). The nitrocellulose membranes were bathed with $\mathrm{ECL}$, and chemiluminescence was registered with the Odyssey Fc Imaging System. Images were analyzed using the Imagel software.

\section{Immunocytochemistry assay}

Non-capacitated and capacitated sperm were fixed as indicated previously. Sperm cells were permeabilized in PBS with $0.1 \%$ Triton for $20 \mathrm{~min}$ at room temperature and washed with PBS. ROCK1(1:50) and ROCK2 (1:50) antibodies were diluted in blocking solution (PBS with $1 \%$ BSA) and incubated on slides overnight at room temperature. The slides were washed three times with PBS and then incubated for $2 \mathrm{~h}$ at $37^{\circ} \mathrm{C}$ with the appropriate TRITC-conjugated secondary antibody diluted in blocking solution. Samples were mounted using glass coverslips and Gelvatol, adequately sealed, and stored at $-20^{\circ} \mathrm{C}$ until the observations. The sperm cells were 
imaged under a confocal laser scanning microscope (Leica TCS SP8) and analyzed using LAS AF Lite (Ver. 2.6.3).

\section{Statistical analysis}

All data are presented as means \pm S.E. Statistical significance was analyzed using $t$-test or ANOVA for comparisons between two groups and multiple comparisons, respectively. SigmaPlot version 11.0 was used for the analysis, and $P<0.05$ was considered statistically significant.

\section{Results}

\section{CDC42 and RHOA antagonists alter capacitation and the acrosome reaction differently}

To define how CDC42 and RHOA antagonists affect capacitation and spontaneous acrosome reaction (sAR), these two physiological states of sperm were quantified by CTC assay and their kinetics were determined from 0 to 90 min of capacitation. Sperm capacitated in the absence of any of the antagonists showed a constant increase in pattern B until 30 min of incubation; after this time, pattern B decreased (Fig. 1B). This decrease coincided with the increase in the AR pattern, which reached its maximum at 90 min of capacitation (Fig. 1C). These events are similar to those observed in mouse sperm (Angeles-Floriano et al. 2016).

When sperm were capacitated in the presence of SecA, $(5 \mu M)$, pattern $B$ increased at 30 min incubation $(75.00 \pm 2.64$ S.E. $)$, similar to the control sample (75.67 \pm 0.88 s.E. Fig. 1B). However, unlike the control, the percentage of pattern $B$ declined only marginally; after 90 min of capacitation in the presence of SecA, pattern B levels maintained values that were not significantly different $(65.67 \pm 4.84$ S.E. $)$ with respect to the values at $30 \mathrm{~min}$ of capacitation (Fig. 1B). This result explains why the sAR does not increase in sperm incubated in the presence of SecA (Fig. 1C). Taken together, these results indicate that CDC42 inhibition has no effect on the normal course of capacitation, although it does block the AR, similar to what happens in mouse sperm (Angeles-Floriano et al. 2016).

When the sperm cells were capacitated in the presence of C3 $(1 \mu \mathrm{M})$, pattern B experienced a slight increase that stopped at $15 \mathrm{~min}$, remaining unchanged until 90 min of incubation (Fig. 1B). The sAR remained unchanged, maintaining similar values from the beginning of capacitation ( $25.00 \pm 2.47$ S.E.) until $90 \mathrm{~min}$ $(19.67 \pm 2.40$ S.E. Fig. 1C). These data confirm that the inhibition of RHOA prevents sperm from experiencing capacitation and, as a consequence, the SAR (Brener et al. 2003).

The AR pattern assessed in the previous results corresponds to sperm that experienced SAR. To know if the different inhibitors used in this work have the same effect on AR induced (iAR) by progesterone, sperm were capacitated in the presence of $\mathrm{C} 3(1 \mu \mathrm{g} / \mathrm{mL})$ or SecA
$(5 \mu \mathrm{M})$ for $50 \mathrm{~min}$. Then, AR was induced by adding progesterone $(10 \mu \mathrm{M})$, and the sperm were incubated for another $20 \mathrm{~min}$. The results show that iAR was significantly higher $(P=0.001)$ than sAR (Fig. 1F). While in sperm capacitated in the presence of $\mathrm{C} 3$ or SecA, the iAR was significantly lower compared with the controls SAR and iAR in sperm capacitated in the absence of the inhibitors (Fig. 1F).

It is important to note that the inhibitors used in the present work (C3, SecA, and Y-2763) at the concentrations used did not alter the viability of the sperm concerning sperm non-capacitated and capacitated sperm in the absence of the inhibitors (Fig. 1G). Only the data of non-capacitated and capacitated at $90 \mathrm{~min}$ are shown because there were no significant changes in sperm viability at times tested $(0,15,30,6075$, and $90 \mathrm{~min})$.

In order to confirm the results obtained employing the CTC technique, the levels of phosphorylation in Tyr of the sperm proteins (PYP) were evaluated by WB. The results show a significant increase in PYP in capacitated sperm $(P=0.001)$ compared to non-capacitated sperm (Fig. 2D and E). When sperm were capacitated in the presence of SecA, PYP levels were similar to that exhibited by sperm capacitated in the absence of SecA (Fig. 2D and E). On the other hand, sperm capacitated in the presence of C3 show significantly lower levels of PYP compared to sperm capacitated in the absence of C3 (Fig. 2D and E).

\section{RHO protein antagonists have various effects on the polymerization of actin}

Different studies have shown that drugs that inhibit RHO proteins such as $\mathrm{C} 3$ toxin (RHOA) and SecA (CDC42)
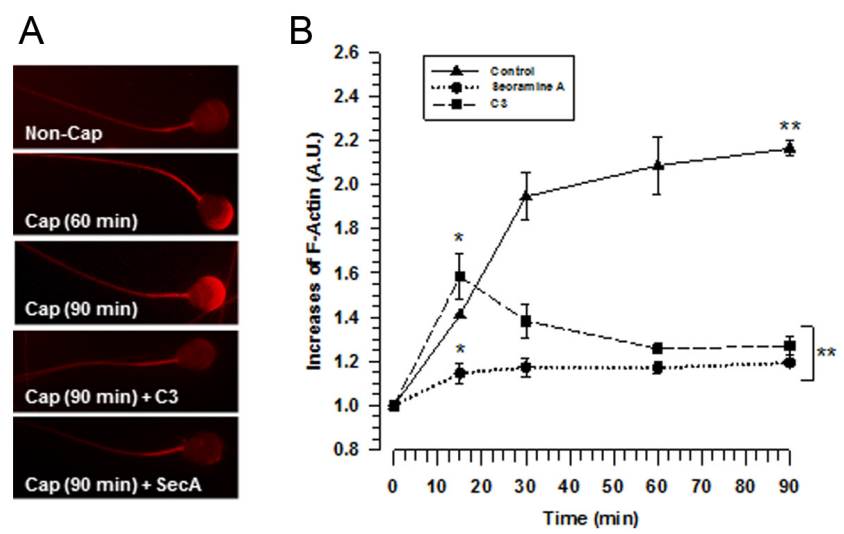

Figure $2 \mathrm{RHO}$ protein antagonists alter actin polymerization differently. (A) Fluorescence patterns of sperm treated with different RHO protein inhibitors and stained with phalloidin-TRITC. (B) Fluorescence levels of phalloidin-TRITC were quantified using the NIS-Elements 3.1 software to define the time course of F-actin during capacitation in the presence or absence of $\mathrm{C} 3$ toxin (C3) or Secramine A (SecA) (Mean \pm S.E.M., $n=3$ independent experiments). $* P=0.044, * * P=0.044$. 
prevent the polymerization of actin during capacitation (Moreno-Fierros et al. 1992, Brener et al. 2003, AngelesFloriano et al. 2016, Roa-Espitia et al. 2016). However, little is known about the temporary effect of these drugs on the remodeling of the actin cytoskeleton. To study the temporary effect of $\mathrm{C} 3$ and SecA, the present study assessed the amount of F-actin present in the sperm at different times of incubation in a capacitation medium in the absence or presence of these actin polymerization antagonists. As can be appreciated in Fig. $1 \mathrm{~A}$, at $90 \mathrm{~min}$ of capacitation, both C3 $(1 \mu \mathrm{g} / \mathrm{mL})$ and SecA $(5 \mu M)$ inhibited actin polymerization. To determine whether these effects were similar at any time of capacitation, the amount of F-actin was assessed at different times of capacitation $(0,15,30,60$, and 90 $\mathrm{min})$. Figure $2 \mathrm{~B}$ exhibits the different effects of these drugs. Control: sperm cells capacitated in the absence of these drugs presented increasing amounts of F-actin levels during capacitation until approximately $30 \mathrm{~min}$ of incubation and a less pronounced increase until 90 min of incubation. Secramine A: Although F-actin levels increased between the beginning of capacitation and after 30 min of capacitation, the increase was not significantly different from the different capacitation times (Fig. 2B). C3: In the case of sperm capacitated in the presence of $\mathrm{C} 3$, the increase in $\mathrm{F}$-actin levels was similar to that observed in the control between 0 to $15 \mathrm{~min}$; after that the levels decayed rapidly to levels comparable to those shown by SecA (Fig. 2B).

\section{Effects of CDC42 inhibition on actin polymerization and the acrosome reaction}

Our previous results suggest that CDC42 could play an important role in actin polymerization during the early stages of capacitation. Four different assays were performed to test the previous hypotheses; in these essays, CDC42 was inhibited at different times of capacitation by adding $\operatorname{Sec} \mathrm{A}(5 \mu \mathrm{M})$. F-actin was evaluated at different times $(0,15,30,60$, and $90 \mathrm{~min})$ in all four essays. Assay 1: Sperm capacitated in the absence of SecA. Results showed that F-actin increased steadily until $30 \mathrm{~min}$ of capacitation and continued increasing less intensely until 90 min (Fig. 3A). Assay 2: SecA added the beginning of capacitation (0 min). Although SecA allowed a small increase in F-actin, especially at 90 min of incubation, the increase was not significant with respect to the different times tested (Fig. 3A). Assay 3: SecA added 15 min after the beginning of capacitation. Results showed an increase in the concentration of F-actin until $30 \mathrm{~min}$ of capacitation, and after this time, the amount of F-actin maintained its level without experiencing changes (Fig. 3A). Assay 4: SecA added 30 min after the beginning of capacitation. In this case, during capacitation, the actin was polymerized as in Assay 1 (Fig. 3A). Interestingly,
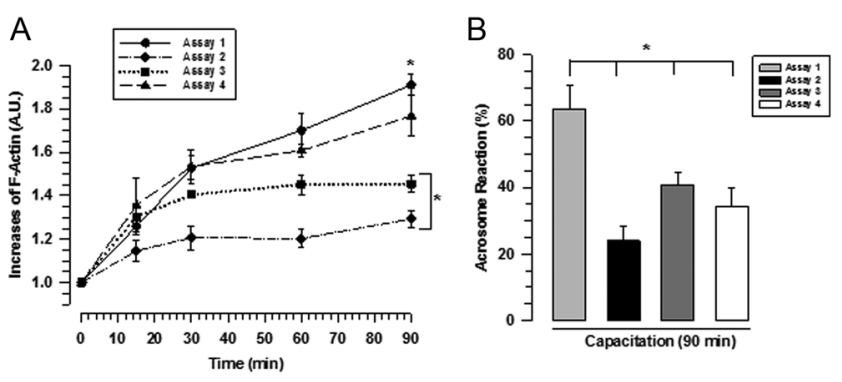

Figure 3 CDC42 inhibition at different times of capacitation has different effects on the polymerization of F-actin, but not on the AR. (A) Sperm were capacitated in the absence or presence of Secramine A $(5 \mu \mathrm{M})$ following four different tests: Assay 1: Sperm capacitated in the absence of Secramine A. Assay 2: Sperm capacitated in the presence of Secramine A. Assay 3: Secramine A added at 15 min of capacitation. Assay 4: Secramine added at $30 \mathrm{~min}$ of capacitation. The fluorescence levels of phalloidin-TRITC were quantified using the NIS-Elements 3.1 software to define the time course of F-actin during capacitation in the presence or absence of Secramine. ${ }^{*} P=0.002$. (B) The acrosomal reaction was assessed at $90 \mathrm{~min}$ of capacitation in the different assays. ${ }^{*} P=0.05$ (mean \pm S.E.M., $n=3$ independent experiments).

the SAR was significantly inhibited with respect to the control in all assays using SecA (Fig. 3B).

\section{RHOA does not increase its activity when CDC42 is inhibited during capacitation}

The results presented thus far suggest that CDC42 has a major effect on RHOA at the beginning of actin polymerization during capacitation. To test this hypothesis, we assessed the activation of CDC42 and RHOA chronologically during capacitation. Figure $4 \mathrm{~A}$ shows that the amount of CDC42-GTP increases significantly $(P=0.01)$ at $10 \mathrm{~min}$ of capacitation with respect to non-capacitated sperm (time $0 \mathrm{~min}$ of incubation). The maximum amount of CDC42-GTP was detected between 10 and 20 min of capacitation, decreasing significantly $(P=0.022)$ at $30 \mathrm{~min}$, but maintaining significantly higher levels with respect to time 0 min $(P<0.05$, Fig. 4A). In the case of RHOAGTP, the immunoblot analysis showed an increase with respect to capacitation time, an increase that was inhibited by the C3 toxin (Fig. 4B). The densitometric analysis of immunoblots showed that the level of RHOAGTP increased significantly $(P=0.001)$ at $20 \mathrm{~min}$ of capacitation compared to non-capacitated sperm (Fig. $4 \mathrm{~A})$. The maximum level of RHOA-GTP was reached until $60 \mathrm{~min}$ of capacitation. These data indicate that the CDC42 and RHOA proteins are activated sequentially: CDC42 is activated early during capacitation, and that is not until CDC42 reaches its maximum activity that RHOA activity increases significantly.

To determine whether the activity of RHOA depends on the activity of CDC42, the levels of RHOA-GTP 


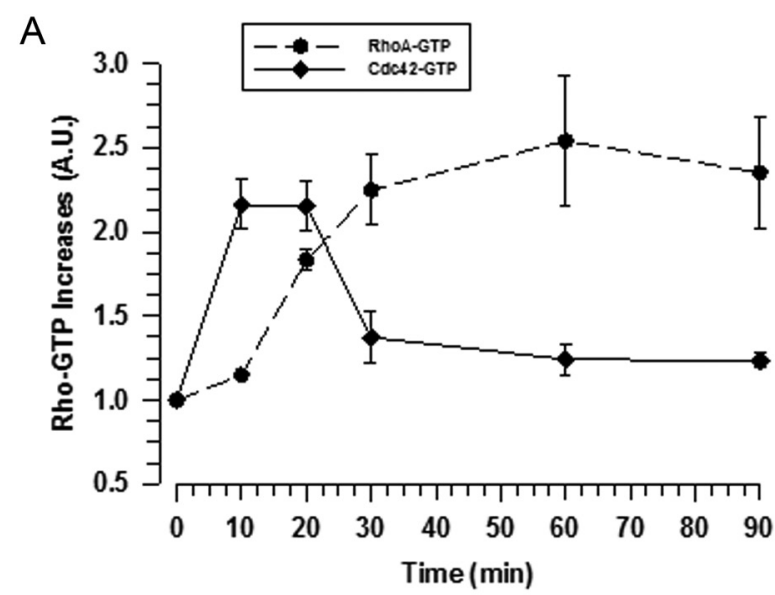

B

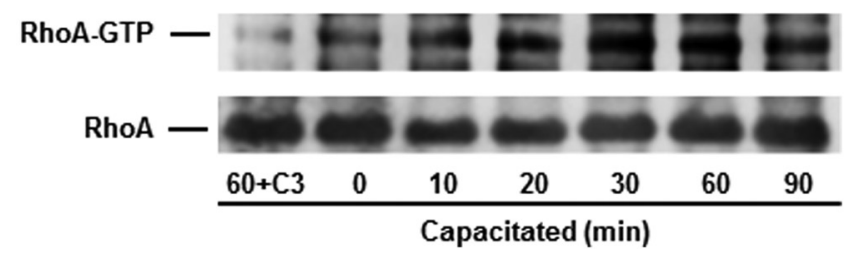

Figure 4 CDC42 and RHOA are activated at different times of capacitation. (A) Whole extracts obtained from sperm capacitated at different times were used to determine the activity of CDC42 by the quantification of CDC42-GTP (see Materials and methods for details). RHOA-GTP was isolated from whole extracts obtained from sperm capacitated at different times (see Materials and Methods for details). Sperm capacitated in the presence of $\mathrm{C} 3(1 \mu / \mathrm{mL})$ were used as control. (B) The WB of RHOA was analyzed by densitometry. The results are expressed as the ratio N/N0, where $\mathrm{N}$ is the total amount of RHOA-GTP and N0 is the total amount of RHOA. Both CDC42 and RHOA normalized concerning non-capacitated (0 min). Means \pm S.E.M., $n=3$ independent experiments. Images are representative of three independent experiments.

from capacitated sperm were assessed using the assays described in a previous section (Effects of CDC42 inhibition on actin polymerization and the acrosome reaction). Assay 1: Sperm capacitated in the absence of SecA. The amount of RHOA-GTP isolated from sperm increased significantly $(P=0.05)$ during capacitation with respect to non-capacitated sperm $(0 \mathrm{~min}$, Fig. 5A and B). Assay 2: SecA added from the beginning of capacitation (0 min). The amount of RHOA-GTP recovered in this assay was similar to that obtained from non-capacitated sperm in the absence of SecA (Fig. 5A and B). Assay 3: The amount of RHOA-GTP recovered from sperm capacitated in the presence of SecA, added 15 min after the beginning of capacitation, was similar to that of non-capacitated sperm in the absence of SecA. Although an increase in the amount of isolated RHOAGTP was observed, such increase was not significantly larger than that of sperm capacitated for 30 or 60 min in the absence of SecA (Fig. 5A and B). Assay 4: The amount of RHOA-GTP isolated from sperm capacitated in the presence of SecA added 30 min after the beginning

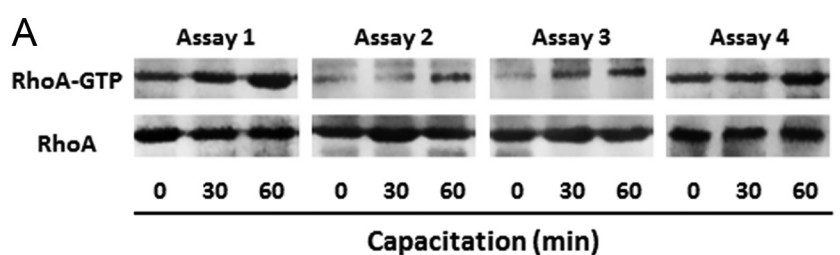

B

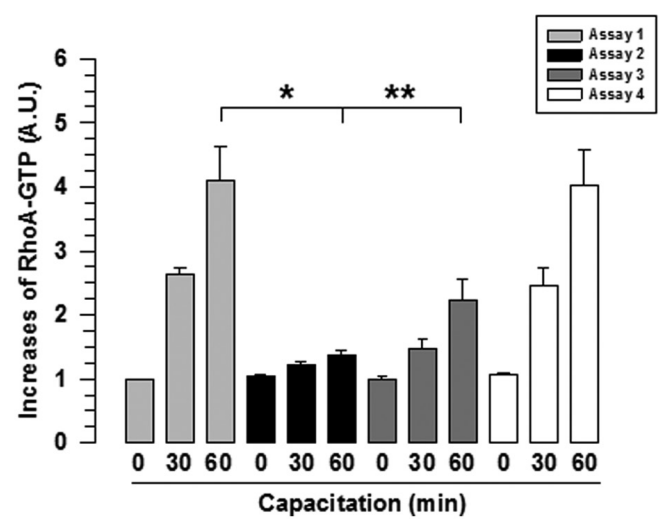

Figure 5 RHOA was not activated when sperm were capacitated in the presence of Secramine A. (A) Whole extracts obtained from sperm capacitated in the absence or presence of SecA $(5 \mu \mathrm{M})$ following four different tests: Assay 1: Sperm capacitated in the absence of SecA. Assay 2: Sperm capacitated in the presence of SecA. Assay 3: SecA added at $15 \mathrm{~min}$ of capacitation. Assay 4: SecA added at $30 \mathrm{~min}$ of capacitation. These extracts were used to isolate RHOA-CDC42 by pull-down. WB images correspond to three independent experiments. (B) RHOA and RHoA-GTP protein bands were analyzed by densitometry, and the results are expressed as an N/NO ratio, where $\mathrm{N}$ is the total amount of RHOA-GTP and $\mathrm{N} 0$ is the total amount of RHOA and normalized with respect to non-capacitated sperm (0 min). Means \pm S.E.M., $n=3$ independent experiments. $* P=0.007, * * P=0.04$.

of capacitation was similar to that of sperm in Assay 1 , both at 30 and 60 min of incubation (Fig. $5 \mathrm{~A}$ and B).

\section{ROCK1 inhibition affects actin polymerization but not the acrosome reaction}

Considering that the main effectors of RHOA-GTP are RHOA 1 and 2 kinases (ROCK1 and 2), we analyzed the role of ROCKs on capacitation, the AR, and actin polymerization. First, we determined the presence of ROCK 1 and 2 in the sperm. Using a specific ROCK1 antibody and Western blotting, we detected only a protein band of approximately $160 \mathrm{kDa}$, both for sperm and the MCF7 cell line, which was used as a control (Fig. $6 \mathrm{~A})$. In the case of ROCK2, it was only detected in the MCF7 cell line and not in sperm (Fig. 6A). Additionally, ROCK1 was located in the acrosomal region and the sperm flagellum. ROCK2 was not found in guinea pig sperm (Fig. 6B). These data suggest that, as with other mammalian sperm, guinea pig sperm express only ROCK1 (Ducummon \& Berger 2006, Romarowski et al. 2015). 
A

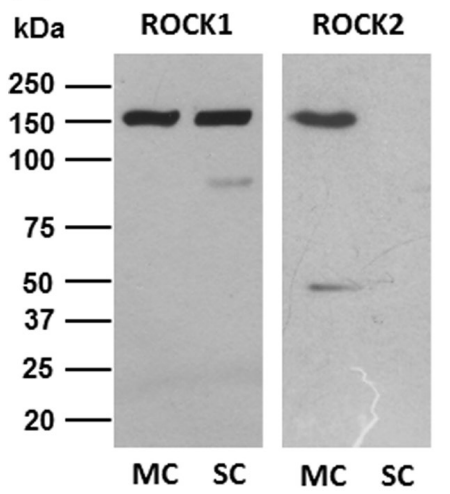

C

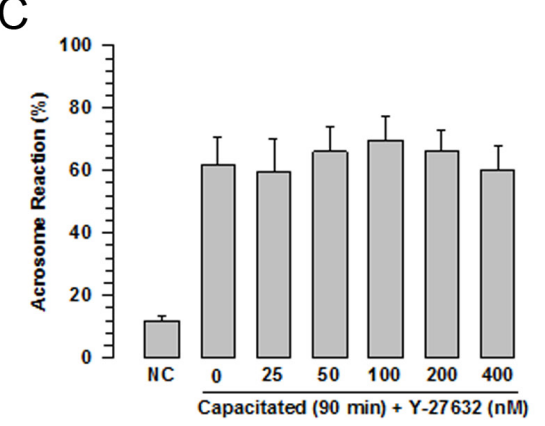

$\mathrm{E}$

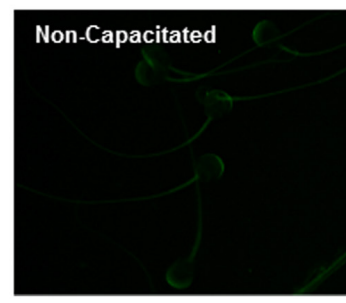

B
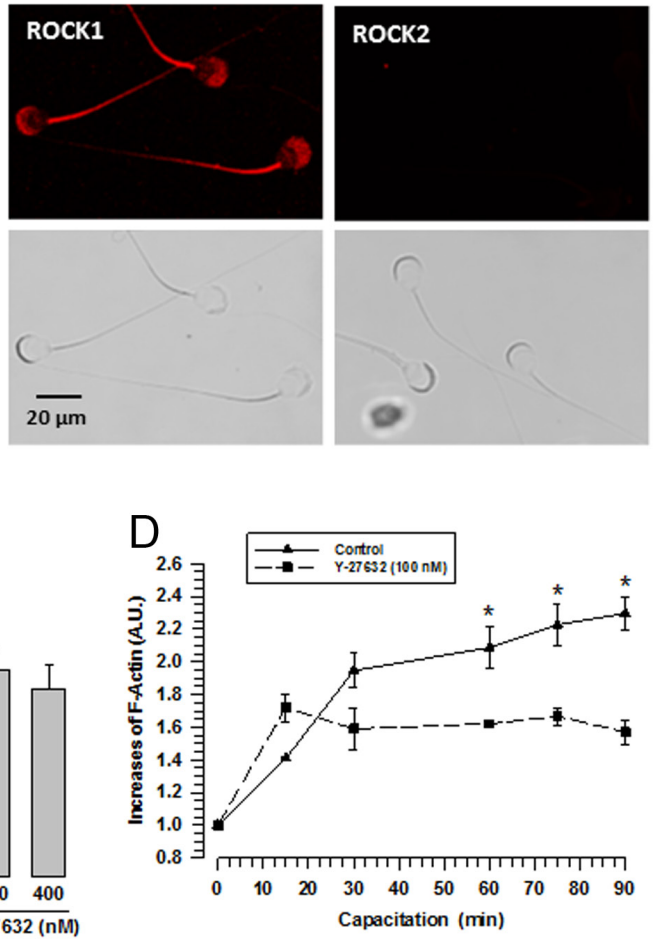

Capacitated $+Y-27632$

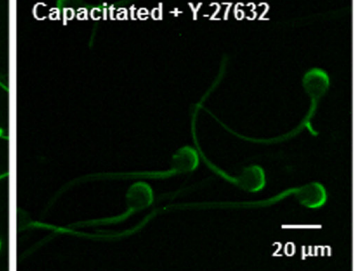

Figure 6 ROCK1 is expressed in guinea pig sperm and does not participate in the acrosomal reaction. (A) Immunodetection of ROCK1 and ROCK2 in guinea pig sperm in complete protein extracts of sperm cells (SC) and MCF7 cells (MC). ROCK1 and ROCK2 proteins were detected using specific antibodies. The images represent independent experiments $(n=3)$. (B) Immunolocation of ROCK1 and ROCK2 in guinea pig sperm. Top panels: immunolocation of ROCK1 and ROCK2. Lower panels bright fields. The images represent of three independent experiments. (C) Effects of ROCK inhibitor (Y-27632) on the AR. Sperm were capacitated in the presence or absence of different concentrations of Y-27632, and its effects on the AR were assessed by CTC assay.

Means \pm S.E.M., $n=3$ independent experiments. (D) Effects of Y-27632 inhibitor on actin polymerization. Sperm were capacitated in the presence or absence of Y-27632, F-actin was stained with phalloidin-FITC, and fluorescence was assessed using the NIS-Elements 3.1 software. Means \pm S.E.M., $n=3$ independent experiments. ${ }^{*} P=0.007$. (E) Sperm were capacitated $(60 \mathrm{~min})$ in the absence or presence of the ROCKs inhibitor, Y-27632 $(100 \mathrm{nM})$, and then stained with phalloidinFITC to reveal F-actin. The images represent three independent experiments.
Using a Y-27632 antagonist, specific for both ROCKs, we determined the role of ROCK1 in the SAR and the polymerization of actin. Sperm were capacitated in the presence of different concentrations of the Y-27632 inhibitor (0-400 nM). After $90 \mathrm{~min}$ of incubation in the capacitation-supportive medium, the SAR was assessed by CTC assay. Results showed that the SAR was unaffected by any concentration of Y-27632 (Fig. 6C). We also determined the kinetics of the capacitation and SAR processes from 0 to $90 \mathrm{~min}$ of incubation. Figure $1 \mathrm{~B}$ shows that in sperm capacitated in the presence of Y-27632 (100 nM) the pattern B increased until $30 \mathrm{~min}$ of capacitation. After $30 \mathrm{~min}$, the pattern B suffered a non-significant decrease that coincides with an accelerated increase in the pattern AR (Fig. 1C), that at 60 min of capacitation is significantly greater $(P=0.001)$ than exhibited by the control, capacitated sperm in the absence of any of the inhibitors. The levels of the pattern AR in the presence of $\mathrm{Y}-27632$ did not exceed those reached by the control (Fig. 1C). In order to know whether the $\mathrm{iAR}$ is affected by $\mathrm{Y}-27632$, sperm were capacitated in the presence of this ROCKs inhibitor $(100 \mathrm{nM})$, and the AR was induced by progesterone $(10 \mu \mathrm{M})$. In essence, iAR in the presence of $\mathrm{Y}-27632$ shows similar values to $\mathrm{iAR}$ in the absence of the inhibitor (Fig. 1F). These results suggest that the development of sperm capacitation is not affected even when ROCK-1 is inhibited. This suggestion was confirmed by analyzing PYP levels. PYP levels were similar for capacitated sperm in the presence or absence of the ROCK1 inhibitor (Fig. $2 \mathrm{D}$ and $\mathrm{E})$.

By contrast, when sperm were capacitated in the presence of Y-27632 (100 nM), the polymerization of actin was significantly modified. In the first $15 \mathrm{~min}$ of capacitation, the amount of F-actin increased to the same extent as the control, sperm capacitated in the absence of Y-27632 (Fig. 6D). After this time, the amount of F-actin remained unchanged, and its levels remained similar until 90 min of capacitation, significantly lower than those determined for the control at the same incubation times (30-90 min, Fig. 6D). Interestingly, the amount of F-actin between 60 to 90 min of capacitation 
is significantly higher $(P \leq 0.01)$ than those shown when sperm were capacitated in the presence of $\mathrm{C} 3$ and SecA (Figs 2B and 6D). The location of F-actin in sperm capacitated in the presence of Y-27632 (100 nM) shows that the majority of the polymerized actin is found in the apical region of the acrosome, while the rest of the head and the flagellum show a lesser fluorescence (Fig. 6E). These results suggest that ROCK1 participates in actin polymerization of the flagella and head, but not in the apical region of the acrosome.

\section{Discussion}

RHO GTPase is well known for its role in the regulation of the dynamics of the actin cytoskeleton, and although there are approximately 22 different $\mathrm{RHO}$ proteins (Narumiya \& Thumkeo 2018), some of the most studied have been RHOA and CDC42. Several studies have reported the expression of different $\mathrm{RHO}$ proteins such as RHOA, RHOB, RHOC, and CDC42 in mammalian sperm (Delgado-Buenrostro et al. 2005, Ducummon \& Berger 2006, Romarowski et al. 2015). Although we are aware that the subcellular locations of RHOA and CDC42 are similar, the acrosomal region and the flagellum (Ducummon \& Berger 2006, Baltierrez-Hoyos et al. 2012, Delgado-Buenrostro et al. 2016), little is known about the involvement of these $\mathrm{RHO}$ proteins in physiological processes such as capacitation, the $A R$, and actin cytoskeleton dynamics. The expression of other RHO proteins, such as RHOB and RHOC, has also been reported in guinea pig and mouse sperm; however, the location of $\mathrm{RHOB}$ is limited to the perinuclear region (Delgado-Buenrostro et al. 2005), while the subcellular location of RHOC is unknown (Romarowski et al. 2015). The present paper provides the first evidence of the relationship between RHOA and CDC42 in the dynamics of the actin cytoskeleton and how they participate in capacitation and the AR.

Our results showed that only SecA inhibits actin polymerization since the first minutes of capacitation, while that F-actin presents a transient increase (15 min of capacitation) in the treatment with C3 (Fig. 1B). Although the sperm were incubated with $\mathrm{C} 31 \mathrm{~h}$ before their placement in the capacitation medium, C3 may require these 15 min to reach an intracellular concentration that allows for the total inhibition of RHOA and, consequently, of actin polymerization. C3 is known not to inhibit CDC42 (Aktories et al. 1995, Just et al. 1995), which suggests that the transient increase could be due to the activity of CDC42. However, these two possibilities fail to explain why actin polymerization is depleted after $15 \mathrm{~min}$ of capacitation in the presence of $\mathrm{C} 3$ even though CDC42 continues to be active after 15 min of capacitation (Fig. 4). Our research suggests that, at the beginning of capacitation ( $0-30 \mathrm{~min})$, CDC42 is required to initiate actin polymerization, perhaps forming nucleation sites through WASP/ARP2/3
(Jaffe \& Hall 2005) proteins present in guinea pig sperm (Delgado-Buenrostro et al. 2005), sites required by $\mathrm{RHOA}$ to regulate the formation of actin filaments (Jaffe \& Hall 2005). This hypothesis is supported by the following facts: (1) only the inhibition of CDC42 prevents the total polymerization of actin from the beginning of capacitation; (2) the increase in actin polymerization is prevented when CDC42 activity is inhibited before 30 min of capacitation, but not after 30 min of capacitation; and (3) RHO protein activation tests indicate that maximum CDC42 activity is reached after $15 \mathrm{~min}$ of capacitation, and after this time, the activity decreases to a baseline level, higher than shown in the noncapacitated state. In addition, RHOA activity reaches significant levels at 20 min of capacitation, increasing its activity constantly during capacitation (Fig. 4). These facts indicate that CDC42 directs actin polymerization during the first $20 \mathrm{~min}$ of capacitation. They also suggest that RHOA takes over in actin polymerization after 20 min of capacitation and that CDC42 activity is possibly not required for actin polymerization but necessary for the activation of other signaling pathways, such as those related with the AR (Baltierrez-Hoyos et al. 2012). This hypothesis is supported by an important finding, the inhibition of CDC42 by SecA, that prevents normal activation of RHOA until before 30 min of capacitation (Fig. 5). These results suggest that the activity of RHOA during the first minutes of capacitation depends on the activity of CDC42 and that such dependence is lost after 30 min of capacitation since, after this time, the activity of RHOA was not prevented by the inhibition of CDC42 (Fig. 5) and actin polymerization occurred normally (Fig. 3A). It should be noted that SecA is a very specific CDC42 inhibitor, which does not alter the activity of other RHO proteins (Pelish et al. 2006); therefore, the inhibition of RHOA activity by CDC42 is not caused by SecA. On the other hand, it has been reported that an insufficient expression of CDC42 prevents the sperm to develop actin polymerization normally, even if RHOA levels are normal (Angeles-Floriano et al. 2016). Taken together, these suggest a cross-talk between CDC42 and RHOA, a cross-talk that plays an important role not only in actin polymerization, but also in capacitation and acrosomal reaction.

Previous studies have shown that RHOA or CDC42 inhibition prevents either capacitation or AR (Brener et al. 2003, Baltierrez-Hoyos et al. 2012, AngelesFloriano et al. 2016). The present study analyzed these events using a technique (CTC) that allowed us to define the physiological states that sperm undergo during their incubation in a medium that supports capacitation (Ward \& Storey 1984, Shi \& Roldan 1995, Mattioli et al. 1996, Cordero-Martinez et al. 2018). Recently, we reported that a low CDC42 expression prevents actin polymerization; however, capacitation is achieved, but AR is interrupted (Angeles-Floriano et al. 2016). The data in the present study are consistent with those reported 
by Angeles-Floriano et al., they show that the majority of sperm remains capacitated without experiencing the AR (Fig. 2). It should be noted that SecA inhibited both, the sAR and $i A R$, in all of our essays (Fig. 3B), suggesting that the participation of CDC42 in the AR goes beyond actin polymerization. We propose that the sperm cells fail to experience the AR because CDC42 is required to form and activate the VAMP2-Sintaxyn 1A complex, which is required in exocytosis processes (Alberts et al. 2006, Nevins \& Thurmond 2006, Bretou et al. 2014), as the AR. Similarly RHOA is required for SNAP-25 activation, another SNARE involved in the process of exocytosis (Horvath et al. 2017). It has been proposed that the inhibition of actin polymerization by $\mathrm{C} 3$, a toxin that blocks the activity of RHO proteins (RHOA, RHOB, and $\mathrm{RHOC}$ ), results in the inhibition of the AR (Brener et al. 2003, Breitbart et al. 2005). Our results suggest that RHOA inhibition prevents capacitation, and as a consequence, the sperm no experience AR (Fig. 2). Together, our results confirm that CDC42 could be more involved in AR than in capacitation, while RHOA, unlike CDC42, would be principally related to capacitation.

The signaling pathway that leads to actin polymerization involves $\mathrm{RHO}$ proteins and ROCK1 or ROCK2 (Fiedler et al. 2008, Amano et al. 2010, Romarowski et al. 2015); therefore, the inhibition of ROCKs during capacitation should inhibit actin polymerization and, consequently, capacitation and the AR (Brener et al. 2003, Breitbart et al. 2005). Our results show that the inhibition of ROCK1 does not interrupt the actin polymerization in the acrosome apical region and the course of the AR, but it is interrupted in the flagellum (Fig. 6D). Similar results have been reported for avian sperm (Ashizawa et al. 2006). The analysis of actin polymerization kinetics during capacitation in the presence of $\mathrm{Y}-27632$ indicates that, when RHOA is inhibited, F-actin increases until 15 min incubation and that their level is preserved until 90 min of capacitation (Fig. 6). This increase occurs in the acrosome apical region apical and may be sufficient for the development of the sAR and iAR. The signaling pathway that links RHOA with capacitation and the AR could involve an effector different from ROCK1, perhaps a member or members of the diaphanous-related formin-1 (mDIA) family (Sakamoto et al. 2012) that would maintain adequate levels of F-actin for capacitation and the AR to happen. Another possibility is that other RHO protein, not inhibited by Y-27632, would be related to the actin polymerization between the external plasma and acrosomal membranes, an event required to avoid early $A R$, and that this sperm process occurs in the usual way (Spungin et al. 1995, Hernandez-Gonzalez et al. 2000, Breitbart et al. 2005). We have recently reported that RAC1 could be related to the formation of this cytoskeleton (Ramirez-Ramirez et al. 2020).

It is important to note that inhibition of ROCK1 during capacitation accelerates AR presentation, possibly as a result of sperm being rapidly subjected to capacitation process. A similar effect has been reported when FAK is inhibited: it inhibits actin polymerization, allows early PYP and consequently the early presentation of AR (RoaEspitia et al. 2016). Therefore, we hypothesize a FAK/ RHOA/ROCK1/Actin polymerization relationship with PYP regulation and therefore with capacitation. Further study is required to prove this hypothesis.

In summary, we have provided evidence indicating that CDC42 and RHOA proteins have specific and essential functions in sperm physiology. CDC42 seems to have an important role in the initiation of actin polymerization during capacitation. Although its inhibition does not impact capacitation, it does affect AR. On the other hand, RHOA would seem to have a predominant role in capacitation, which consequently impacts AR. This conclusion is supported by the fact that ROCK1 would appear to have no participation in the AR. We also identified that RHOA activity is dependent on CDC42 activity and that they act in tandem during capacitation; CDC42 initiates the polymerization of actin and after RHOA takes over. However, both RHO proteins are essential for the normal remodeling of the actin cytoskeleton to take place during capacitation. Finally, we suggest that the different $\mathrm{RHO}$ proteins (CDC42, RAC1, and RHOA) present in mammalian sperm regulate actin polymerization in specific regions of sperm and thus participate in the diverse physiological processes that sperm experience to acquire fertilizing ability

\section{Declaration of interest}

The authors declare that there is no conflict of interest that could be perceived as prejudicing the impartiality of the research reported.

\section{Funding}

This study was supported by Consejo Nacional de Ciencia y Tecnología (CONACYT): CB-284183 to E O H G. Scholarship 262875 to T M R. Consejo Mexiquense de Ciencia y Tecnología (COMECYT): 17BEPD0050-11 to T M R.

\section{Author contribution statement}

T M R carried out the experiment and analyzed the data. R B H helped to carry out the experiment. A L R E helped supervise the project, standardized the CTC assay and administered the project. E O H G conceived of the presented idea, planned the experiments, analyzed the data and wrote the manuscript.

\section{Acknowledgements}

The authors wish to thank Jaime Escobar, Chief Manager at Unidad de Microscopia Confocal (Cell Biology Department, 
CINVESTAV-IPN), for providing access to confocal facilities. The authors thank the Kirchhausen Lab (Harvard Medical School) and the Hammond Lab (University of Louisville) for providing secramine $A$, which was synthesized by Bo Xu and GB Hammond of the University of Louisville.

\section{References}

Aktories K, Jung M, Bohmer J, Fritz G, Vandekerckhove J \& Just I 1995 Studies on the active-site structure of C3-like exoenzymes: involvement of glutamic acid in catalysis of ADP-ribosylation. Biochimie 77 326-332. (https://doi.org/10.1016/0300-9084(96)88142-9)

Alberts P, Rudge R, Irinopoulou T, Danglot L, Gauthier-Rouviere C \& Galli T 2006 Cdc42 and actin control polarized expression of TI-VAMP vesicles to neuronal growth cones and their fusion with the plasma membrane. Molecular Biology of the Cell 17 1194-1203. (https://doi. org/10.1091/mbc.e05-07-0643)

Amano M, Nakayama M \& Kaibuchi K 2010 Rho-kinase/ROCK: a key regulator of the cytoskeleton and cell polarity. Cytoskeleton 67 545-554. (https://doi.org/10.1002/cm.20472)

Angeles-Floriano T, Roa-Espitia AL, Baltierrez-Hoyos R, CorderoMartinez J, Elizondo G \& Hernandez-Gonzalez EO 2016 Absence of aryl hydrocarbon receptor alters CDC42 expression and prevents actin polymerization during capacitation. Molecular Reproduction and Development 83 1015-1026. (https://doi.org/10.1002/mrd.22736)

Ashizawa K, Wishart GJ, Katayama S, Takano D, Maeda M, Arakawa E \& Tsuzuki Y 2006 Effects of calpain and Rho-kinase inhibitors on the acrosome reaction and motility of fowl spermatozoa in vitro. Reproduction 131 71-79. (https://doi.org/10.1530/rep.1.00588)

Azamar Y, Uribe S \& Mujica A 2007 F-actin involvement in guinea pig sperm motility. Molecular Reproduction and Development 74 312-320. (https://doi.org/10.1002/mrd.20578)

Baltierrez-Hoyos R, Roa-Espitia AL \& Hernandez-Gonzalez EO 2012 The association between CDC42 and caveolin-1 is involved in the regulation of capacitation and acrosome reaction of guinea pig and mouse sperm. Reproduction 144 123-134. (https://doi.org/10.1530/REP-11-0433)

Bastian Y, Roa-Espitia AL, Mujica A \& Hernandez-Gonzalez EO 2010 Calpain modulates capacitation and acrosome reaction through cleavage of the spectrin cytoskeleton. Reproduction 140 673-684. (https://doi. org/10.1530/REP-09-0545)

Bernabo N, Berardinelli P, Mauro A, Russo V, Lucidi P, Mattioli M \& Barboni B 2011 The role of actin in capacitation-related signaling: an in silico and in vitro study. BMC Systems Biology 5 47. (https://doi. org/10.1186/1752-0509-5-47)

Breitbart H, Cohen G \& Rubinstein S 2005 Role of actin cytoskeleton in mammalian sperm capacitation and the acrosome reaction. Reproduction 129 263-268. (https://doi.org/10.1530/rep.1.00269)

Brener E, Rubinstein S, Cohen G, Shternall K, Rivlin J \& Breitbart H 2003 Remodeling of the actin cytoskeleton during mammalian sperm capacitation and acrosome reaction. Biology of Reproduction 68 837-845. (https://doi.org/10.1095/biolreprod.102.009233)

Bretou M, Jouannot O, Fanget I, Pierobon P, Larochette N, Gestraud P, Guillon M, Emiliani V, Gasman S, Desnos C et al. 2014 Cdc42 controls the dilation of the exocytotic fusion pore by regulating membrane tension. Molecular Biology of the Cell 25 3195-3209. (https://doi. org/10.1091/mbc.E14-07-1229)

Brito LF, Barth AD, Bilodeau-Goeseels S, Panich PL \& Kastelic JP 2003 Comparison of methods to evaluate the plasmalemma of bovine sperm and their relationship with in vitro fertilization rate. Theriogenology 60 1539-1551. (https://doi.org/10.1016/s0093-691x(03)00174-2)

Cabello-Agueros JF, Hernandez-Gonzalez EO \& Mujica A 2003 The role of F-actin cytoskeleton-associated gelsolin in the guinea pig capacitation and acrosome reaction. Cell Motility and the Cytoskeleton 56 94-108. (https://doi.org/10.1002/cm.10135)

Cordero-Martinez J, Reyes-Miguel T, Rodriguez-Paez L, GardunoSiciliano L, Maldonado-Garcia D, Roa-Espitia AL \& HernandezGonzalez EO 2018 TMEM16A inhibition impedes capacitation and acquisition of hyperactivated motility in guinea pig sperm. Journal of Cellular Biochemistry 119 5944-5959. (https://doi.org/10.1002/ jcb.26789)
Delgado-Buenrostro NL, Hernandez-Gonzalez EO, Segura-Nieto M \& Mujica A 2005 Actin polymerization in the equatorial and postacrosomal regions of guinea pig spermatozoa during the acrosome reaction is regulated by $\mathrm{G}$ proteins. Molecular Reproduction and Development $\mathbf{7 0}$ 198-210. (https://doi.org/10.1002/mrd.20192)

Delgado-Buenrostro NL, Mujica A, Chiquete-Felix N, Deciga-Alcaraz A, Medina-Reyes El, Uribe-Carvajal S \& Chirino YI 2016 Role of Wasp and the small GTPases RhoA, RhoB, and Cdc42 during capacitation and acrosome reaction in spermatozoa of English guinea pigs. Molecular Reproduction and Development 83 927-937. (https://doi.org/10.1002/ mrd.22657)

Ducummon CC \& Berger T 2006 Localization of the Rho GTPases and some Rho effector proteins in the sperm of several mammalian species. Zygote 14 249-257. (https://doi.org/10.1017/S0967199406003790)

Fiedler SE, Bajpai M \& Carr DW 2008 Identification and characterization of RHOA-interacting proteins in bovine spermatozoa. Biology of Reproduction 78 184-192. (https://doi.org/10.1095/ biolreprod.107.062943)

Fouquet JP, Kann ML \& Dadoune JP 1990 Immunoelectron microscopic distribution of actin in hamster spermatids and epididymal, capacitated and acrosome-reacted spermatozoa. Tissue and Cell 22 291-300. (https://doi.org/10.1016/0040-8166(90)90004-s)

Gervasi MG \& Visconti PE 2016 Chang's meaning of capacitation: a molecular perspective. Molecular Reproduction and Development 83 860-874. (https://doi.org/10.1002/mrd.22663)

Hall JE, Fu W \& Schaller MD 2011 Focal adhesion kinase: exploring Fak structure to gain insight into function. International Review of Cell and Molecular Biology 288 185-225. (https://doi.org/10.1016/B978-0-12386041-5.00005-4)

Hernandez-Gonzalez EO, Lecona-Valera AN, Escobar-Herrera J \& Mujica A 2000 Involvement of an F-actin skeleton on the acrosome reaction in guinea pig spermatozoa. Cell Motility and the Cytoskeleton $\mathbf{4 6}$ 43-58. (https://doi.org/10.1002/(SICl)1097-0169(200005)46:1<43::AIDCM5>3.0.CO;2-1)

Horvath D, Tamas I, Sipos A, Darula Z, Becsi B, Nagy D, Ivan J, Erdodi F \& Lontay B 2017 Myosin phosphatase and RhoA-activated kinase modulate neurotransmitter release by regulating SNAP-25 of SNARE complex. PLOS ONE 12 e0177046. (https://doi.org/10.1371/journal. pone.0177046)

Itach SB, Finklestein M, Etkovitz N \& Breitbart H 2012 Hyper-activated motility in sperm capacitation is mediated by phospholipase D-dependent actin polymerization. Developmental Biology $\mathbf{3 6 2}$ 154-161. (https://doi.org/10.1016/j.ydbio.2011.12.002)

Jaffe AB \& Hall A 2005 Rho GTPases: biochemistry and biology. Annual Review of Cell and Developmental Biology 21 247-269. (https://doi. org/10.1146/annurev.cellbio.21.020604.150721)

Just I, Selzer J, Jung M, van Damme J, Vandekerckhove J \& Aktories K 1995 Rho-ADP-ribosylating exoenzyme from Bacillus cereus. Purification, characterization, and identification of the NAD-binding site. Biochemistry 34 334-340. (https://doi.org/10.1021/bi00001a041)

Maldonado-Garcia D, Salgado-Lucio ML, Roa-Espitia AL, Reyes-Miguel T \& Hernandez-Gonzalez EO 2017 Calpain inhibition prevents flotillin re-ordering and Src family activation during capacitation. Cell and Tissue Research 369 395-412. (https://doi.org/10.1007/s00441-017-2591-2)

Mattioli M, Barboni B, Lucidi P \& Seren E 1996 Identification of capacitation in boar spermatozoa by chlortetracycline staining. Theriogenology $\mathbf{4 5}$ 373-381. (https://doi.org/10.1016/0093-691x(96)81099-5)

Megnagi B, Finkelstein M, Shabtay O \& Breitbart H 2015 The role and importance of cofilin in human sperm capacitation and the acrosome reaction. Cell and Tissue Research 362 665-675. (https://doi. org/10.1007/s00441-015-2229-1)

Moreno-Fierros L, Hernandez EO, Salgado ZO \& Mujica A 1992 F-actin in guinea pig spermatozoa: its role in calmodulin translocation during acrosome reaction. Molecular Reproduction and Development 33 172-181. (https://doi.org/10.1002/mrd.1080330209)

Mujica A, Moreno-Rodriguez R, Naciff J, Neri L \& Tash JS 1991 Glucose regulation of guinea-pig sperm motility. Journal of Reproduction and Fertility 92 75-87. (https://doi.org/10.1530/jrf.0.0920075)

Naresh S \& Atreja SK 2015 Actin polymerization: an event regulated by tyrosine phosphorylation during buffalo sperm capacitation. Reproduction in Domestic Animals 50 1047-1053. (https://doi. org/10.1111/rda.12635) 
Narumiya S \& Thumkeo D 2018 Rho signaling research: history, current status and future directions. FEBS Letters 592 1763-1776. (https://doi. org/10.1002/1873-3468.13087)

Nevins AK \& Thurmond DC 2006 Caveolin-1 functions as a novel Cdc42 guanine nucleotide dissociation inhibitor in pancreatic beta-cells. Journal of Biological Chemistry 281 18961-18972. (https://doi.org/10.1074/jbc. M603604200)

Pelish HE, Peterson JR, Salvarezza SB, Rodriguez-Boulan E, Chen JL, Stamnes M, Macia E, Feng Y, Shair MD \& Kirchhausen T 2006 Secramine inhibits Cdc42-dependent functions in cells and Cdc42 activation in vitro. Nature Chemical Biology 2 39-46. (https://doi.org/10.1038/ nchembio751)

Peterson RN, Bozzola JJ, Hunt WP \& Darabi A 1990 Characterization of membrane-associated actin in boar spermatozoa. Journal of Experimental Zoology 253 202-214. (https://doi.org/10.1002/jez.1402530210)

Ramirez-Ramirez D, Salgado-Lucio ML, Roa-Espitia AL, Fierro R, Gonzalez-Marquez H, Cordero-Martinez J \& Hernandez-Gonzalez EO 2020 Rac1 is necessary for capacitation and acrosome reaction in guinea pig spermatozoa. Journal of Cellular Biochemistry 121 2864-2876. (https://doi.org/10.1002/jcb.29521)

Roa-Espitia AL, Hernandez-Rendon ER, Baltierrez-Hoyos R, Munoz-Gotera RJ Cote-Velez A, Jimenez I, Gonzalez-Marquez H \& Hernandez-Gonzalez EO 2016 Focal adhesion kinase is required for actin polymerization and remodeling of the cytoskeleton during sperm capacitation. Biology Open 5 1189-1199. (https://doi.org/10.1242/bio.017558)

Romarowski A, Battistone MA, La Spina FA, Puga Molina Ldel C, Luque GM, Vitale AM, Cuasnicu PS, Visconti PE, Krapf D \& Buffone MG 2015 PKA-dependent phosphorylation of LIMK1 and cofilin is essential for mouse sperm acrosomal exocytosis. Developmental Biology $\mathbf{4 0 5}$ 237-249. (https://doi.org/10.1016/j.ydbio.2015.07.008)

Sakamoto S, Ishizaki T, Okawa K, Watanabe S, Arakawa T, Watanabe N \& Narumiya S 2012 Liprin-alpha controls stress fiber formation by binding to $\mathrm{mDia}$ and regulating its membrane localization. Journal of Cell Science 125 108-120. (https://doi.org/10.1242/jcs.087411)

Salvolini E, Buldreghini E, Lucarini G, Vignini A, Lenzi A, Di Primio R \& Balercia G 2013 Involvement of sperm plasma membrane and cytoskeletal proteins in human male infertility. Fertility and Sterility 99 697-704. (https://doi.org/10.1016/j.fertnstert.2012.10.042)
Shi QX \& Roldan ER 1995 Bicarbonate/CO2 is not required for zona pellucida- or progesterone-induced acrosomal exocytosis of mouse spermatozoa but is essential for capacitation. Biology of Reproduction 52 540-546. (https://doi.org/10.1095/biolreprod52.3.540)

Sosnik J, Miranda PV, Spiridonov NA, Yoon SY, Fissore RA, Johnson GR \& Visconti PE 2009 Tssk6 is required for Izumo relocalization and gamete fusion in the mouse. Journal of Cell Science 122 2741-2749. (https://doi. org/10.1242/jcs.047225)

Spungin B, Margalit I \& Breitbart H 1995 Sperm exocytosis reconstructed in a cell-free system: evidence for the involvement of phospholipase C and actin filaments in membrane fusion. Journal of Cell Science $\mathbf{1 0 8}$ 2525-2535.

Stival C, Puga Molina Ldel C, Paudel B, Buffone MG, Visconti PE \& Krapf D 2016 Sperm capacitation and acrosome reaction in mammalian sperm. Advances in Anatomy, Embryology, and Cell Biology 220 93-106. (https://doi.org/10.1007/978-3-319-30567-7_5)

Visconti PE, Bailey JL, Moore GD, Pan D, Olds-Clarke P \& Kopf GS 1995a Capacitation of mouse spermatozoa. I. Correlation between the capacitation state and protein tyrosine phosphorylation. Development 121 1129-1137.

Visconti PE, Moore GD, Bailey JL, Leclerc P, Connors SA, Pan D, OldsClarke P \& Kopf GS 1995 b Capacitation of mouse spermatozoa. II. Protein tyrosine phosphorylation and capacitation are regulated by a CAMP-dependent pathway. Development 121 1139-1150.

Ward CR \& Storey BT 1984 Determination of the time course of capacitation in mouse spermatozoa using a chlortetracycline fluorescence assay. Developmental Biology 104 287-296. (https://doi.org/10.1016/00121606(84)90084-8)

Received 29 November 2019

First decision 20 January 2020

Revised manuscript received 22 May 2020

Accepted 18 June 2020 